and take a pride in being fit for fire-fighting and other duties. You can do the same, and this treatment will help you to get accustomed to raid noises."

\section{Conditioning and Abreaction}

Though the procedure was intended to be a means of "conditioning" cases to noxious sounds, it soon became evident that it could be used as a speedy and practical method of abreacting patients. The process of letting a patient re-live terrifying emotional experiences has a therapeutic effect. As a measure for producing abreaction the employment of war noises is much simpler than hypnosis or hypnonarcosis. It is quick,-effective, and does not demand too great technical skill. The patient is enabled to recall terrifying incidents which had determined his symptoms, and by expressing them in the secure atmosphere of the hospital his self-control and confidence are helped. The following case illustrates the use of the method as an abreactive agent.

A private aged 22 who was in good health until shelled badly in France developed acute anxiety symptoms, thereafter tending to become worse when in bombing raids in this country. After admission to hospital he was given a course of " sound-therapy," and on the first application he became very agitated, volunteering the information that the noise " brought it all back again." The blood pressure and pulse rate showed marked increase after hearing warfare noises. Though the patient was aware that the sounds were artificial, he reacted briskly when the stimulus was given, vivid memories of the initial traumatic experience being recalled.

It was established in a number of cases that this procedure could easily reveal a wealth of psychological material, and by releasing emotional tension have a beneficial effect.

Some people cannot stand up to the stress of noises without help. It is not a question of " scrimshanking" but of constitutional make-up. They can be helped by realizing that knowledge and a sense of security will see them through. Giving them sane simple explanation and advice and getting them accustomed to disturbing stimuli increases their stability and sense of security and relieves apprehension and exaggerated fears. Our experience would indicate that the repetition of noxious stimuli is of value in restoring function in these cases. The principle of conditioning is very much that of the horseman who mounts immediately after a fall in order to prevent the association of fear and riding.

One man who complained of trembling, palpitation, and loss of control during air raids since the Dunkirk evacuation was conditioned to warfare noises in a week, and during subsequent air-raid alerts was no longer disturbed, being finally discharged to duty. Another soldier, with a similar history, at first reacted so strongly to the sounds given that he rushed screaming from the room. At the end of six days' treatment he was perfectly calm and showed no reaction whatever.

\section{Conclusion}

Air attack is being employed on all fronts to demoralize our people. It is now evident, however, that the anticipated number of psychiatric casualties as a result of air raids has not been justified. Actually there has been no increase in the incidence of neurosis or psychosis in our bombed cities. A corporate sense of discipline, preparedness, and individual effort has maintained morale. Fear has to a large extent been dissipated by the activity of fire-fighting and other defence measures. Fear, which is simply a normal protective instinct, can be countered by enlightenment, and aerial bombardment is unlikely to achieve its demoralizing object if the experience is not a complete surprise. Apprehension and anxiety concerning air raids are more likely to affect those who are inactive and have not been accustomed to warfare noises. Repetition of bombardment noises would appear to assist in raising the power of endurance and in enabling the individual to stand up to this new form of attack.

Our thanks are due to various members of the B.B.C. staff for their valuable help in producing the records used in this investigation. We are also indebted to Colonel G. W. Will, O.B.E., for permission to investigate cases under his care.

\section{CHEMOTHERAPY IN ACUTE MIDDLE-EAR DISEASE: "MASKED MASTOIDITIS"}

\author{
BY \\ C. A. HUTCHINSON, F.R.C.S.Ed. \\ Major, R.A.M.C. ; Otologist to a Military Hospital
}

I have recently had three cases (quoted in detail below) referred to me in quick succession which have much exercised my mind on the subject of chemotherapy in acute disease of the middle ear.

In view of Dr. J. B. Jessiman's (1941) article on the subject, which drew forth prompt criticism from $\mathrm{Mr}$. Lionel Colledge (1941), it would seem that there is ample justification for uttering a warning against putting too great reliance on drugs of the sulphonamide group. They have admittedly proved of marked value in the control of infections of the middle-ear cleft, but it is a mistake-which may have tragic consequences-to assume that, quite irrespective of whether myringotomy has or has not been done, all is of necessity well with the patient because the temperature has fallen, mastoid tenderness has disappeared, and the other symptoms and signs have cleared up. Such cases, indeed, call for very careful watching, since the sulphonamides can "mask" a mastoiditis most effectively, while serious complications may develop in the most alarmingly sudden manner.

Furthermore, it should be noted that in each of the cases quoted below sulphapyridine has been employed. Now, this agent is excellent for pneumococcal infections, but even its most enthusiastic supporters must admit it to be of very considerably less value than sulphanilamide where the infection is of streptococcal origin. After all, pneumococci are, it is true; responsible for many cases of middle-ear infection, but a number of cases are undoubtedly due to streptococci or other organisms. We should therefore be on our guard against thinking as it were in terms of sulphapyridine to the exclusion of sulphanilamide. Such blind faith can only result in a proportion of failures, and these will inevitably bring quite unwarranted discredit on a group of most valuable therapeutic agents.

It is suggested that the correct procedure in every case of threatening or frankly developed middle-ear infection is to take swabbings from the tonsils, nasopharynx, and/or purulent discharge itself (whether the result of perforation or myringotomy) and, if bacteriological examination reveals the presence of streptococci, then sulphanilamide (and not sulphapyridine) should be administered. It is only by such conscientious use of the appropriate member of the group that we can secure more consistently satisfactory results and so gain for these agents that confidence in them which is their just due.

Lastly, while agreeing with most of the relevant comments by Mr. R. Thomas (1941), I cannot find myself in agreement with his expressed wish that "the day will soon come when this simple operation [he specifies "paracentesis"] will become part of the armamentarium of every general practitioner." In the first place, paracentesis has been rightly 
displaced from favour by the far more effective procedure of myringotomy; and, secondly, " every general practitioner" does not possess the experience and nicety of judgment which alone can decide whether myringotomy still has a reasonable chance of averting an acute mastoid or whether things have already gone too far for anything short of immediate mastoidectomy to have a hope of relieving the condition and possibly preventing a catastrophe.

\section{Case I}

A gunner aged 22 was admitted to a military hospital on January 17, 1941, with a history of left otalgia followed by otorrhoea. Temperature $99.4^{\circ}$, pulse 80 . " Exacerbation of an old C.O.M.S.(L)" was diagnosed. Next day temperature tended to swing between $100.6^{\circ}$ and $97.4^{\circ}$. On the 19 th it settled to rermal, and he was given guttae glyc. and phenol, fomentations, s.v.r. drops, and mist. aspirin. He was discharged to a convalescent home on the 25 th, with normal temperature but profuse otorrhoea. From January 28 to 31 sulphapyridine, 1 gramme four-hourly, was given. Temperature was very slightly irregular above and below normal. He was transferred to a convalescent depot on February 7.

On February 10, when referred to me, there was thin somewhat offensive left otorrhoea, slight deafness in the left ear, mediumsized postero-inferior perforation, but no vertigo or tinnitus. He was returned to the convalescent depot with the recommendation that he be kept under close observation and that dry mopping and insufflation of $1 \%$ iodoboric powder be carried out. On the 13th he was readmitted to hospital with general malaise and severe pain behind the left ear. Otorrhoea was profuse and the left ear was pushed somewhat forward ; there was no mastoid tenderness, but the patient looked ill. Subacute left mastoiditis was diagnosed. 'The next day left epitympano-mastoidectomy wias performed. Very extensive involvement of the mastoid region was found. The bone was of mixed cellular and sclerotic type. Aditus, attic, antrum, and cells contained pus under some pressure. Healing by first intention was secured, and recovery was uneventful; the otorrhoea soon dried up, and there was very little loss of hearing.

\section{Case II}

A lance-corporal aged 21 was referred to me at a military hospital on January 21, 1941, with a history of having first noticed left-sided otorrhoea while on leave. There was slight deafness, but no pain ; trismus, said to date from the extraction of a left lower wisdom tooth, was present. He stated that he had been treated by a civilian doctor and given, among other things, tablets of sulphapyridine, but no details as to dosage, etc., were available. He looked ill. There was a moderate amount of thin non-offensive otorrhoea, left cervical adenitis, and mediumsized postero-inferior perforation, but no mastoid tenderness.

He was admitted and kept under close observation, with dry mopping of the otorrhoea, counter-irritation over the cervical glands, gargles, and mentholization. During the next few days the trismus improved, but the temperature showed a slight tendency to swing between $98^{\circ}$ and $99^{\circ}$. In the afternoon of January 26 there was a sudden exacerbation, with malaise, swelling of the left parotid region, slight left facial paresis, and gradual filling up of a fluctuating swelling on the posterior aspect of the lobule of the left ear. On the 27 th he had a definite toxic appearance; the above-mentioned swellings had increased and the left facial paresis had deepened. Temperature normal; pulse 98. Left epitympano-mastoidectomy was performed. There was generalized osteomyelitis in an acellular mastoid with a perforation near the tip, "tracking" into the lobule of the ear and into the parotid region. This was thoroughly cleared and the wound packed open, secondary suture being performed on February 5. The wound then healed by first intention, the facial paresis recovered completely, the otorrhoea dried up, and the perforation in the drum healed. The hearing is good.

\section{Case III}

A second-lieutenant aged 28 was admitted to a hospital on February 18, 1941, with severe otalgia in the left ear of sudden onset and a history of acute left otitis media two years previously. Slight pulsatile left otorrhoea was present, but no mastoid tenderness. Sulphapyridine and a spirit-and-flavine wick were used, and on March 11 he was given a week's sick leave, the ear being then dry and all symptoms relieved. On March 15 diplopia developed, and on the 18th he consulted the eye specialist, who referred him to me. He gave the following history: For some days he had had fairly severe neuralgic pain centred somewhat vaguely between the left ear and the left eye, which had gradually changed to a dull ache behind the left eye; then on the 15 th, as stated above, he had for the first time noticed the diplopia. On examination I found complete paralysis of the left external rectus; in other words, he presented the complete picture of the Gradenigo symptom-complex, indicating the presence of petrositis. A small perforation was found in the anterior portion of Shrapnell's membrane, from which a thin trickle of pus was escaping. Radiographs showed considerable relative radio-opacity of the left mastoid region and the petrous pyramid, with loss of the cellular outlines.

A left Schwartze mastoidectomy was performed on March 21. There was widespread involvement of the mastoid cells, which contained pus, while the mucosa was thickened. Two polypi were impacted in the aditus, and on their removal pus under considerable pressure escaped from the attic region and the middle ear. Healing took place by first intention, and convalescence was uneventful. All symptoms have been removed, while with the assistance of electrical stimulation of the paralysed muscle complete recovery from the paralysis has been secured and the diplopia has disappeared. The perforation in the drum has healed and the hearing seems to be normal.

\section{REFERENCES}

Colledge, L. (1941). British Medical Journal, 1, 455. Jessiman, J. B. (1941). Ibid., 1, 399. Thomas, R. (1941). Ibid., 1, s71.

\section{Medical Memoranda}

\section{Intestinal Haemorrhage as a Complication of Sulphonamide Therapy}

The recent occurrence of melaena in two children under treatment with sulphonamide drugs stimulated an inquiry into the recorded incidence of this complication. The scanty references in the literature and the absence of records of its occurrence in this country make these notes and observations of value.

\section{CASE REPORTS.}

Case 1.-A boy aged 5 was admitted to the Southport Infirmary on January 23, 1941, with a history of severe vomiting of two days' duration. Lumbar puncture produced $4 \mathrm{c.cm}$. of turbid fluid from which meningococci were later grown on culture. Next day he was given 0.5 gramme of sulphapyridine soluble intramuscularly and transferred to the borough isolation hospital. On admission he was drowsy and irritable, and the temperature was $98.4^{\circ} \mathrm{F}$. He did not appear to be very ill. Soluseptasine 0.5 gramme intramuscularly was ordered four-hourly. Next day after five injections his temperature had remained normal, but head retraction and opisthotonos were pronounced. lumbar puncture produced no fluid, and cisternal puncture only $2 \mathrm{c.cm}$. of opalescent fluid. Sulphapyridine soluble 0.5 gramme intramuscularly was ordered three-hourly. On January 27 the boy was much improved and took 0.5 gramme of sulphapyridine by mouth four times daily for four days. On January 31 he appeared normal, and received three 0.5 -gramme doses of sulphapyridine, and on February 1 two doses of 0.5 gramme each. In the night of February 1 he passed a small tarry motion, and on February 2 two large melaena stools. He was very pale, but his condition did not give rise to anxiety. Parenteral salines were given. As we were unable to account for the melaena a blood film was made late at night and suggested a diagnosis of myeloid leukaemia. The temperature was $99^{\circ} \mathrm{F}$., the spleen was not palpable or enlarged to percussion, the liver was not enlarged, no enlarged glands could be felt, no petechiae were seen, the urine was normal, and there was no evidence of jaundice. The blood film, however, showed a considerable increase of white cells, estimated at more than 100,000 , of which $92 \%$ were polymorphs, $6 \%$ myelocytes, and $2 \%$ lymphocytes. The red cells were rather pale, and showed anisocytosis ; $2 \%$ nucleated red 